\title{
2-way coupling the hydrological land surface model PROMET with the regional climate model MM5
}

\author{
F. Zabel and W. Mauser \\ Department of Geography, Ludwig-Maximilians-Universität (LMU), Munich, Germany \\ Correspondence to: F. Zabel (f.zabel@iggf.geo.uni-muenchen.de) \\ Received: 21 May 2012 - Published in Hydrol. Earth Syst. Sci. Discuss.: 13 June 2012 \\ Revised: 30 January 2013 - Accepted: 3 April 2013 - Published: 2 May 2013
}

\begin{abstract}
Most land surface hydrological models (LSHMs) consider land surface processes (e.g. soil-plant-atmosphere interactions, lateral water flows, snow and ice) in a spatially detailed manner. The atmosphere is considered as exogenous driver, neglecting feedbacks between the land surface and the atmosphere. On the other hand, regional climate models (RCMs) generally simulate land surface processes through coarse descriptions and spatial scales but include land-atmosphere interactions. What is the impact of the differently applied model physics and spatial resolution of LSHMs on the performance of RCMs? What feedback effects are induced by different land surface models? This study analyses the impact of replacing the land surface module (LSM) within an RCM with a high resolution LSHM.

A 2-way coupling approach was applied using the LSHM PROMET $\left(1 \times 1 \mathrm{~km}^{2}\right)$ and the atmospheric part of the RCM MM5 $\left(45 \times 45 \mathrm{~km}^{2}\right)$. The scaling interface SCALMET is used for down- and upscaling the linear and non-linear fluxes between the model scales.

The change in the atmospheric response by MM5 using the LSHM is analysed, and its quality is compared to observations of temperature and precipitation for a $4 \mathrm{yr}$ period from 1996 to 1999 for the Upper Danube catchment. By substituting the Noah-LSM with PROMET, simulated non-biascorrected near-surface air temperature improves for annual, monthly and daily courses when compared to measurements from 277 meteorological weather stations within the Upper Danube catchment. The mean annual bias was improved from -0.85 to $-0.13 \mathrm{~K}$. In particular, the improved afternoon heating from May to September is caused by increased sensible heat flux and decreased latent heat flux as well as more incoming solar radiation in the fully coupled PROMET/MM5 in comparison to the NOAH/MM5 simulation. Triggered by
\end{abstract}

the LSM replacement, precipitation overall is reduced; however simulated precipitation amounts are still of high uncertainty, both spatially and temporally. The distribution of precipitation follows the coarse topography representation in MM5, resulting in a spatial shift of maximum precipitation northwards of the Alps. Consequently, simulation of river runoff inherits precipitation biases from MM5. However, by comparing the water balance, the bias of annual average runoff was improved from $21.2 \%$ (NOAH/MM5) to $4.4 \%$ (PROMET/MM5) when compared to measurements at the outlet gauge of the Upper Danube watershed in Achleiten.

\section{Introduction}

Land surface models designed for hydrological studies (LSHMs - land surface hydrological models) need meteorological data as input in order to simulate the pathway of water and energy at the land surface. This can be provided by measurements or regional climate models (RCMs). The latter are often used for hydrological impact studies on climate change scenarios. However, most LSHMs consider the atmosphere as an exogenous model driver only, applying a 1-way coupling approach and usually a correction of the systematic biases of temperature and precipitation (Marke et al., 2011a; Senatore et al., 2011) (see Fig. 1, left panel). The 1way coupled model chain includes two different land surface models describing the same land surface processes, but differently. By not allowing for feedback between the downstream LSHM and the atmosphere of the RCM, inconsistencies occur when driving the LSHM offline with RCM output (Zabel et al., 2012). 


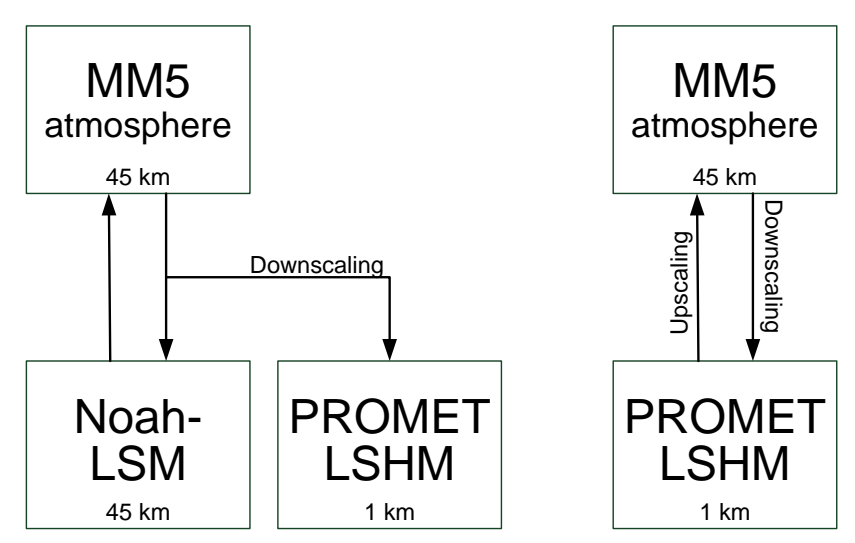

Fig. 1. Schematic illustration of applying the original Noah-LSM (left panel) as the land surface representation within MM5, applying a 1-way coupling with the PROMET LSHM (second panel from left), and applying a 2-way coupling of the PROMET LSHM with the MM5 atmosphere (right panel).

Physically based LSHMs are usually designed to simulate small-scale river basins on a high spatial resolution. This allows for modelling physical processes with high process and spatial detail. LSHMs have been intensely validated reproducing gauge measurements and have recently been extended from small- to large-scale river basins on the order of 1 million $\mathrm{km}^{2}$. The physically based models aim at understanding in great detail the interactions between the different land surface compartments, namely soil, vegetation, and snow and ice in producing the resulting river runoff (GarciaQuijano and Barros, 2005; Kuchment et al., 2006; Kunstmann et al., 2008; Ludwig and Mauser, 2000; Ludwig et al., 2003; Mauser and Bach, 2009; Schulla and Jasper, 1999). Some are not calibrated with measured runoff, and thereby, in a strict sense, they conserve mass and energy at the land surface. They include detailed descriptions of vertical and lateral soil water and energy flows, vegetation dynamics and related flow regulations, snow and ice dynamics, as well as energy and mass exchange with the atmosphere. For adequately modelling runoff over mountainous terrain with RCM forcing, a bias correction of the RCM data is necessary (Marke et al., 2011b).

Land surface modules (LSMs), designed for use within RCMs, are developed at coarse spatial resolution on continental scales. They use a comparatively simple physical description of the land surface processes with simple parameterizations, in order to keep computational demands low (Chen and Dudhia, 2001; Henderson-Sellers et al., 1995, 1996; Pitman, 2003; Pitman and Henderson-Sellers, 1998; Wood et al., 1998). In recent years, they have become more and more complex, considering vegetation dynamics, biogeochemical processes, surface and subsurface hydrology, dynamic development of snowpack and representations of urban and artificial areas as well as lakes (van den Hurk et al., 2011). In terms of their physical skill, LSMs and LSHMs have converged. Nevertheless, a gap remains in the spatial resolution of RCMs and LSHMs.

As shown in multiple studies, an improvement of both physical parameterization and spatial resolution improves RCM simulation results (Hagemann et al., 2001; Zängl, 2007a). Therefore, Chen and Dudhia (2001) stated that 2way coupling a LSHM with a RCM potentially seems to be a very powerful approach. Mölders and Raabe (1997), for example, applied a 2 -way coupling approach to a $24 \mathrm{~h}$ weather prediction forecast for a small domain of $225 \times 150 \mathrm{~km}^{2}$ due to limited computational resources. They showed that even for the short timescale, the 2-way coupling allows production of subgrid-scale land surface fluxes (soil wetness, evapotranspiration) in more detail and affects cloudiness.

\section{Materials and method}

The RCM applied in this study is the fifth-generation Mesoscale Model (MM5) (Grell et al., 1994), developed by the Pennsylvania State University (Penn State) and the National Center for Atmospheric Research (NCAR). It was modified and adapted to our specific simulation requirements and our specific model domain (Pfeiffer and Zängl, 2010; Zängl, 2002). MM5 is used in climate mode with a horizontal spatial resolution of $45 \mathrm{~km}$ and an internal time step of 135 seconds. ECMWF ERA-40 reanalysis data (Uppala et al., 2005) are used to drive the MM5 model solutions 6hourly at the lateral boundaries of the nesting domain that covers the European continent with 79 grid boxes in eastwest and 69 grid boxes in north-south directions (Pfeiffer and Zängl, 2010).

The Noah-LSM (Chen and Dudhia, 2001), an original component of MM5, is a physically based LSM designed for use in atmospheric applications such as MM5. It uses the same spatial resolution as the atmosphere model. It has been developed with the goal of a simple but robust parameterization, taking the most important aspects of land surface hydrology into account (Chen and Dudhia, 2001). As a physically based LSHM, PROMET uses a more hydrological view on the land surface with a more detailed spatial resolution of $1 \mathrm{~km}$ and different physical formulations from the Noah-LSM (Zabel et al., 2012). Detailed model descriptions of PROMET can be found in Mauser and Bach (2009) and Muerth and Mauser (2012).

An enhanced 2-way coupling approach, which takes care of the different spatial resolutions of the atmospheric and the land surface component, is used in this study to couple the LSHM PROMET bi-directionally with the RCM MM5 for the model domain of Central Europe (Zabel et al., 2012). The Noah-LSM is replaced with PROMET and the bi-directional scaling tool SCALMET. PROMET's results of scalar surface fluxes (latent and sensible heat, short- and long-wave outgoing radiation and momentum) are linearly upscaled to $45 \mathrm{~km}$. These upscaled fluxes serve as the lower boundary conditions 
for the MM5 atmosphere, and MM5's downscaled results $(1 \mathrm{~km})$ provide the inputs for PROMET. The non-scalar radiation temperature at the surface or at the top of the vegetation canopy, according to the existence of vegetation, is handed to MM5. This is needed to initialize the convection scheme at each coupling time step. It is calculated from the upscaled emissivity and the upscaled emission of long-wave radiation of the PROMET land surface using the StefanBoltzmann law. The adjustable coupling time step for exchanging the fluxes between both models in both directions was set to 540 simulation seconds in the current study. This allows PROMET to run synchronously with MM5, which uses an internal time step of 135 simulation seconds. Within the 540 model seconds, the upscaled fluxes are assumed to be constant.

SCALMET assures the conservation of mass and energy during the up- and downscaling process. In order to guarantee a consistent coupling between the models, a bias correction is not applied in this study. PROMET maintains mass and energy at the land surface and is not calibrated with measured discharge. A more detailed model comparison between PROMET and Noah-LSM and methodological explanation of the coupling approach between PROMET and MM5 is given in Zabel et al. (2012).

Within this paper, the results of three different configurations are compared with observation data (see Fig. 1):

- Noah-LSM bi-directionally (also named interactively, fully or 2-way) coupled with the atmospheric part of MM5 (= NOAH/MM5).

- PROMET (also named 1-way or offline) driven with MM5 output through the scaling interface SCALMET (= PROMET).

- PROMET bi-directionally (also named interactively, fully or 2-way) coupled with MM5 through the scaling interface SCALMET (= PROMET/MM5).

The simulations took place for the Upper Danube catchment over a 4 yr period from 1996-1999. Measurements from 277 meteorological weather stations, spatially interpolated to the Upper Danube catchment, are used for validation. The catchment is situated in Central Europe, has an area of $76.653 \mathrm{~km}^{2}$, and is characterized by a complex terrain, covering parts of the Alps in southern Germany, Austria, Switzerland and Italy. Altitudes reach from 4049 m a.s.l. at Piz Bernina to $287 \mathrm{~m}$ a.s.l. at the catchment's outlet at the gauge in Achleiten. The lowlands north of the Alps are characterized by heterogeneous land and soil patterns, intense agriculture, and high population density. The prevailing climate is characterized by the temperate latitudes with an annual precipitation gradient ranging from $550 \mathrm{~mm}$ in the northern part of the catchment to more than $2000 \mathrm{~mm}$ in the Alps.

\section{Results and discussion}

\subsection{Differences between PROMET and Noah-LSM}

Figure 2 compares the land surface energy fluxes between Noah-LSM and PROMET for the Upper Danube catchment, both driven with the same meteorological data. The compared area means are calculated for Noah-LSM over an area of $45 \times 45 \mathrm{~km}$ grid boxes, whereby for PROMET for the same area of $1 \mathrm{~km} 1 \times 1 \mathrm{~km}$ grid boxes.

Differences result from different assumptions of underlying land use and soil, different land use and soil parameterization and different model physics. While offline driven, PROMET simulates less long-wave outgoing radiation and more short-wave outgoing radiation than Noah-LSM. The lower PROMET long-wave outgoing radiation is mainly due to lower values of land surface emissivity, while the higher amount of reflected short-wave radiation results from more heterogeneous land use and land cover in PROMET. PROMET has a higher number of land use/cover classes with high albedo values, such as urban area or rock. Further, snow cover increased short-wave reflection, especially from March to May, due to the increased spatial resolution in PROMET. The more detailed underlying topography results in higher elevations in the Alpine area. Thus, the snowpack remains longer in the higher altitudes, affecting short-wave reflection. In the Noah-LSM the coarse spatial resolution results in lower peak altitudes in the Alps and, hence, earlier snow melts.

Overall, net radiation for the Upper Danube catchment is higher by $8 \mathrm{~W} \mathrm{~m}^{-2}$ in the 1-way coupled PROMET simulation. The higher net radiation is distributed more into sensible than into latent heat (Zabel et al., 2012). As a result, the Bowen ratio is higher in the offline PROMET simulation.

Evapotranspiration is considerably lower due to impervious surfaces, such as urban area and rock, that do not contribute to transpiration in PROMET, while Noah-LSM mainly implements a mixture of cropland and forest (Zabel et al., 2012) for the Upper Danube. Consequently, sensible heat is higher in summer but lower in the winter months (Fig. 2) due to snow cover effects in the PROMET simulation in the Alpine area. While energy is used for snow melt in the PROMET simulation, available net radiation is given as sensible heat in the Noah-LSM. The higher spatial resolution in PROMET results in a more detailed modelling of the snow cover, especially in the spatially heterogeneous Alps, with a strong impact on the sensible heat flux. Thus, more energy is invested into snow melt in the PROMET simulation, explaining the overall lower heat fluxes in the PROMET simulation although net radiation is a little higher.

\subsection{Atmosphere responses}

By replacing Noah-LSM with PROMET and a bi-directional scaling interface, a full interactive coupling with the 

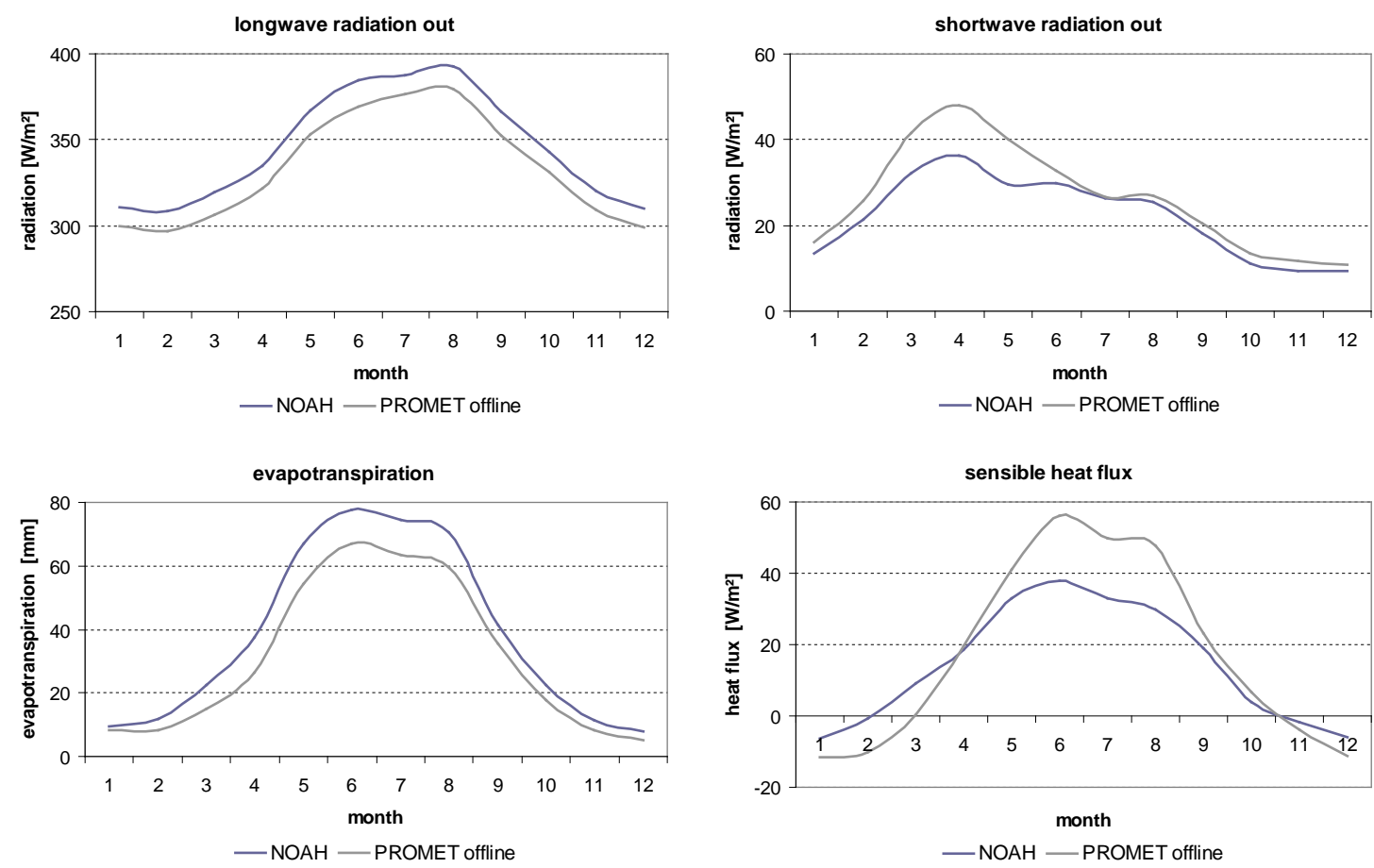

Fig. 2. Spatially averaged monthly land surface mass and energy fluxes (long-wave outgoing radiation, short-wave reflection, evapotranspiration, sensible heat flux) for the Upper Danube catchment simulated with Noah-LSM and with PROMET for the years 1996-1999.

atmospheric part of MM5 is achieved. Triggered by the replacement, the atmospheric part of MM5 responds by changed planetary boundary layer height, changed solar radiation, and changed temperature and precipitation for annual, monthly and diurnal cycles.

\subsubsection{Planetary boundary layer}

The tendency of higher sensible heat flux, as shown in the offline PROMET results, affects the planetary boundary layer height in the bi-directionally coupled PROMET/MM5 approach. As can be seen in Fig. 3, the planetary boundary layer height is higher in summer and lower in winter when using PROMET. This has far-reaching implications to the moisture content of air masses as well as the stability of stratification. Sensible heat is a critical parameter affecting cloud fraction, convection and, thus, precipitation as well as solar radiation.

\subsubsection{Solar incoming radiation}

Total incoming radiation, as the sum of direct and diffuse radiation, is higher when using the PROMET land surface (Noah-LSM: $106 \mathrm{~W} \mathrm{~m}^{-2}$; PROMET: $112 \mathrm{~W} \mathrm{~m}^{-2}$ ). Spatially interpolated measurements of radiation $\left(117 \mathrm{~W} \mathrm{~m}^{-2}\right)$ from 277 meteorological stations are compared to simulation results in Fig. 4. The monthly incoming short-wave radiation is higher in the summer months and closer to the measurements while the influence of the land surface on the atmospheric conditions is lower in winter. The basic shape of the

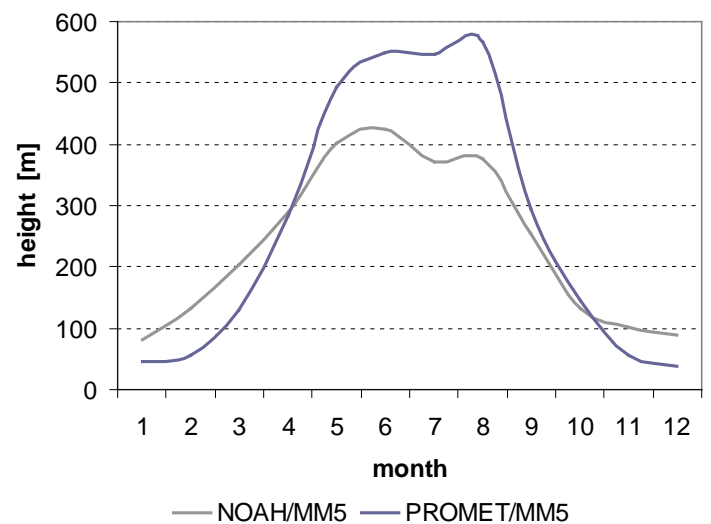

Fig. 3. Monthly course of the planetary boundary layer height (1996-1999) of 2-way coupled PROMET/MM5 and NOAH/MM5 simulations.

PROMET and Noah-LSM curves is similar since it is mainly controlled by the passing low-pressure systems imposed onto the simulations by the ERA-40 lateral boundary forcing.

\subsubsection{Temperature}

The higher solar incoming radiation as well as lower evaporative cooling in PROMET results in higher annual mean near-surface air temperature, from 5.93 to $6.65^{\circ} \mathrm{C}$, in the fully coupled PROMET/MM5 simulations. The higher temperatures occur north of the Alps and near the city of 


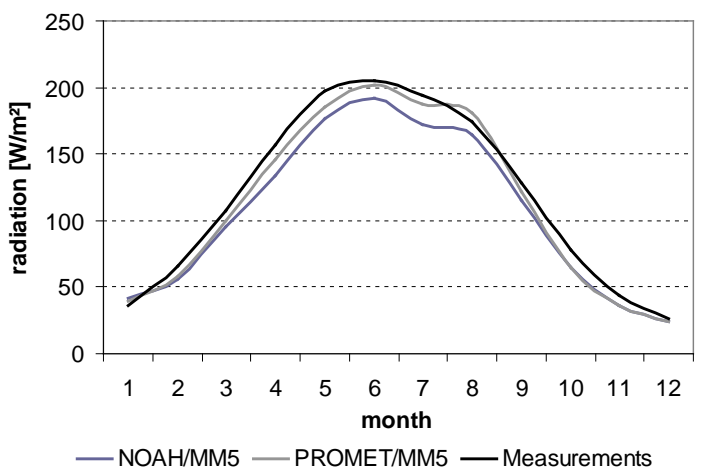

Fig. 4. Monthly course of the total incoming short-wave radiation (1996-1999) of 2-way coupled PROMET/MM5 and NOAH/MM5 simulations.

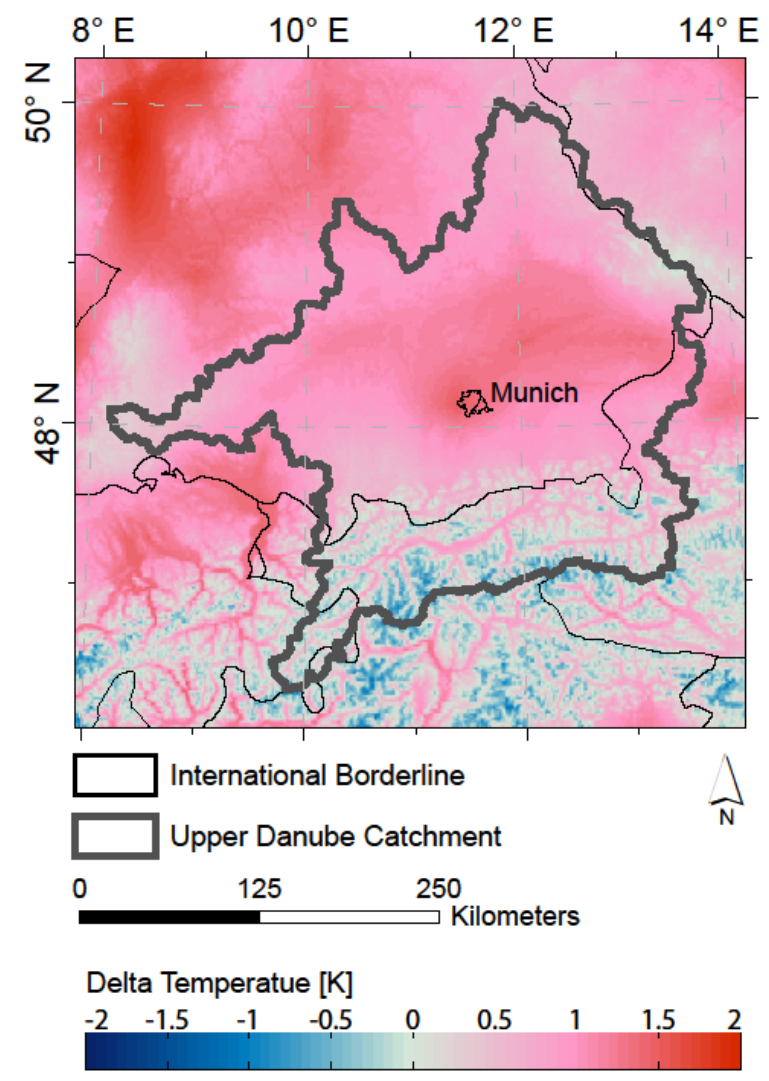

Fig. 5. Difference plot between 2-way coupled PROMET/MM5 and NOAH/MM5 annual mean near-surface air temperature in the Upper Danube catchment, downscaled to $1 \mathrm{~km}$ by using SCALMET.

Munich (Fig. 5). Average temperature from 277 meteorological weather stations results in $6.78^{\circ} \mathrm{C}$ for the Upper Danube catchment and the respective years. Annual bias was reduced from -0.85 to $-0.13 \mathrm{~K}$. In addition, the monthly behaviour was improved in fully coupled PROMET/MM5 simulations when compared to measurements (see Fig. 6).

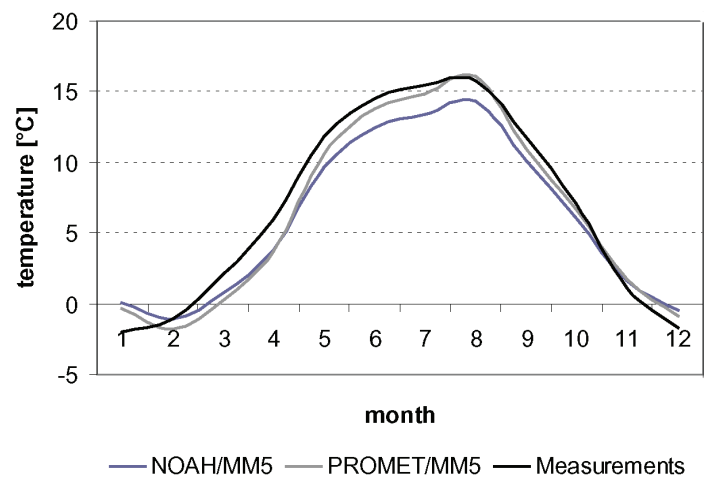

Fig. 6. Monthly mean temperature of 2-way coupled PROMET/MM5 and NOAH/MM5 simulations in comparison with measurements in the Upper Danube catchment.

Figure 7 shows the simulated diurnal cycle of the nearsurface air temperature for NOAH/MM5, PROMET/MM5 and measurements. The impact of the land surface model used is marginal in the winter months due to low energy inputs on the land surface. The diurnal cycle is strongly affected by the changed land surface in the summer months. Here, by using PROMET, near-surface air temperature heats up faster and stronger. A cold bias of up to $2 \mathrm{~K}$ observed in the NOAH/MM5 simulation, especially in the afternoon hours in summer, is similar to the results of Pfeiffer and Zängl (2010). In the PROMET-driven simulations, the diurnal course in the summer months can be reproduced much more consistently. In particular, the maximum temperature can be reproduced considerably better.

In August for example, the observed mean maximum temperature is $19.7^{\circ} \mathrm{C}$; the NOAH/MM5 simulations reach $16.9^{\circ} \mathrm{C}$ in the afternoon hours, while the bi-directionally coupled PROMET/MM5 simulations lead to a mean maximum daily temperature of $19.0^{\circ} \mathrm{C}$ due to the changed lower boundary conditions.

\subsubsection{Precipitation}

The observed annual precipitation for the area of the Upper Danube is $1045 \mathrm{~mm}$. While the NOAH/MM5 approach calculated $1180 \mathrm{~mm}$, the fully coupled PROMET/MM5 approach simulated $1095 \mathrm{~mm}$. Thus, annual bias was reduced from 12.9 to $4.8 \%$. Winter and spring precipitations are clearly overestimated (Fig. 8) in both MM5 simulations. Simulated precipitation amounts are lower in the summer months when coupling the PROMET land surface with MM5, while winter and spring precipitations hardly differ (Fig. 8).

Convective precipitation events are strongly linked to the underlying land surfaces. Since the land surface classifications and extensions differ between the two models, different amounts of convective precipitation events are observed between the simulations, in particular in the warm, high energy 

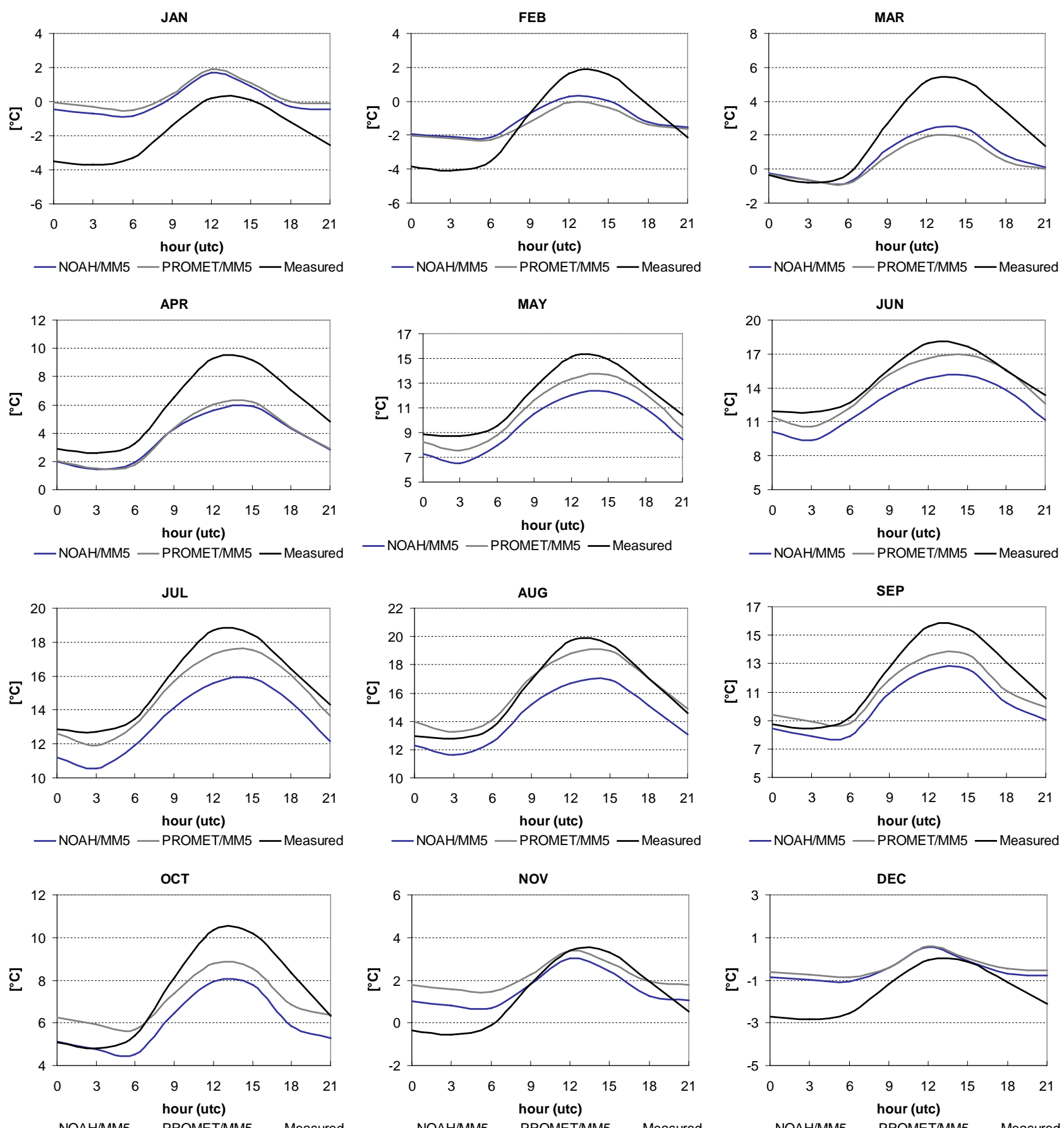

Fig. 7. Monthly mean diurnal cycle (1996-1999) of the near-surface air temperature (3-hourly) for the Upper Danube catchment.

summer months. The lower values in the monthly precipitation from May to September in the results of PROMET/MM5 are due to the $20 \%$ decrease in the simulation of convective precipitation, versus a $9 \%$ decrease in non-convective precipitation (Fig. 8).

Heavy precipitation events, such as in May 1999, are not properly reproduced in the Upper Danube in either simu- lation, as heavy precipitations are generally underestimated (Zängl, 2007b).

Further, Zängl (2007a) found a resolution-dependence that drastically affects the MM5 model skill in the Alpine part of the model. By refining the mesh size from 9 to $1 \mathrm{~km}$, the topography in the atmosphere model was enhanced and the simulated precipitation considerably improved. However, the coarse resolution of the MM5 atmosphere in both simulations 


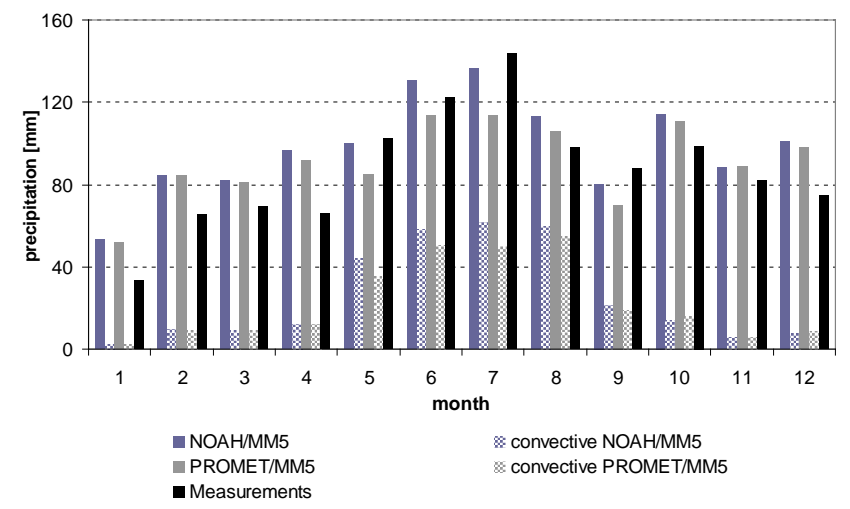

Fig. 8. Monthly convective and total precipitation of MM5 simulations coupled with Noah-LSM and PROMET compared to measurements.

$(45 \mathrm{~km})$ is not suitable for reproducing precipitation properly in the Alps and the foothills of the Alps. Due to the coarse spatial resolution, the spatial patterns of precipitation follow the coarse spatial resolution of the underlying MM5 topography $\left(45 \times 45 \mathrm{~km}^{2}\right)$. The scale mismatch to the $1 \mathrm{~km}$ topography of PROMET, therefore, leads to inadequate spatial shifts and biases in precipitation that cannot be corrected without a bias correction.

This resulted in a northwards shift of precipitation away from the Alps, when compared to observations and overestimated precipitation especially in winter (Pfeiffer and Zängl, 2010). Consequently, precipitation is generally overestimated in the Alpine foreland and underestimated in the Alps (see Fig. 9).

The PROMET simulation shows a lower annual overestimation in the Alpine foreland and a higher annual underestimation in the Alpine regions. Simulated precipitation improved in the northern part of the Upper Danube catchment, but little change was observed in the Alps and at low relief.

\subsection{Feedback effects}

\subsubsection{Evapotranspiration}

Triggered by the land surface replacement in MM5, changed atmospheric conditions, such as the increased temperature and solar radiation, feed back to the land surface in the bidirectional coupling case. Figure 10 shows the impact of the feedback on simulated evapotranspiration. While it increases between May and August, it decreases slightly from September to April in PROMET/MM5.

The change of evapotranspiration in the fully coupled PROMET/MM5 simulations highly depends on the simulated soil moisture. In the Upper Danube catchment, the wilting point is hardly ever reached, and evapotranspiration can increase in summer due to higher air temperatures without being affected by limited soil moisture.
Table 1. Measured annual mean runoff at the outlet of the Upper Danube catchment at Achleiten in comparison with simulated runoff of NOAH/MM5 and PROMET/MM5 in either 1-way or 2way coupled configuration.

\begin{tabular}{lc}
\hline Model configuration & Runoff \\
\hline NOAH & $1712 \mathrm{~m}^{2} \mathrm{~s}^{-1}$ \\
PROMET, 1-way coupled & $1583 \mathrm{~m}^{2} \mathrm{~s}^{-1}$ \\
PROMET, 2-way coupled & $1474 \mathrm{~m}^{2} \mathrm{~s}^{-1}$ \\
Measurements & $1412 \mathrm{~m}^{2} \mathrm{~s}^{-1}$ \\
\hline
\end{tabular}

\subsubsection{Water balance}

By the use of PROMET's baseflow, interflow and surface runoff as well as channel hydraulic components, simulated time series of monthly, daily and hourly runoff can be compared against hourly gauge measurements (Mauser and Bach, 2009). Noah-LSM has the ability to model surface runoff formation but lacks the option to simulate lateral and river channel flow.

However, it is not the intention of this study to estimate the ability of bias-corrected RCM inputs to reproduce runoff in the Upper Danube watershed. Since a bias correction would have been counterproductive in this study, biases of the RCM, particularly precipitation biases, are handed over to the land surface components and, therefore, drastically affect runoff simulations.

Consequently, analogously to precipitation, a spatially detailed analysis of simulated river runoff unearths strong uncertainties in the Alps and the Alpine foreland. Simulated annual average river runoff at the catchment's outlet was compared to the observed annual average runoff at the outlet of the Upper Danube catchment in Achleiten, which was determined to be $1412 \mathrm{~m}^{3} \mathrm{~s}^{-1}$ for the years considered. The results are shown in Table 1.

Mean surface runoff $(\mathrm{mm})$ simulated by the Noah-LSM for the Upper Danube catchment and converted into the catchment's discharge is $1712 \mathrm{~m}^{3} \mathrm{~s}^{-1}$. Thus, NOAH/MM5 strongly overestimates annual mean runoff. One-way coupling of PROMET with MM5 results in a simulated average lateral river runoff of $1583 \mathrm{~m}^{3} \mathrm{~s}^{-1}$ and a considerable improvement from the NOAH/MM5 case. The full 2-way coupling of PROMET and MM5 leads to a simulated average river runoff of $1474 \mathrm{~m}^{3} \mathrm{~s}^{-1}$. This value can be considered to compare quite well with the observed $1412 \mathrm{~m}^{3} \mathrm{~s}^{-1}$. Thus, the annual bias could be reduced from $21.1 \%$ (Noah-LSM) to $4.4 \%$ (2-way coupled PROMET).

\section{Conclusions}

In this study, we investigated the impacts of replacing the Noah-LSM of the RCM MM5 with the LSHM PROMET for the Upper Danube catchment. 

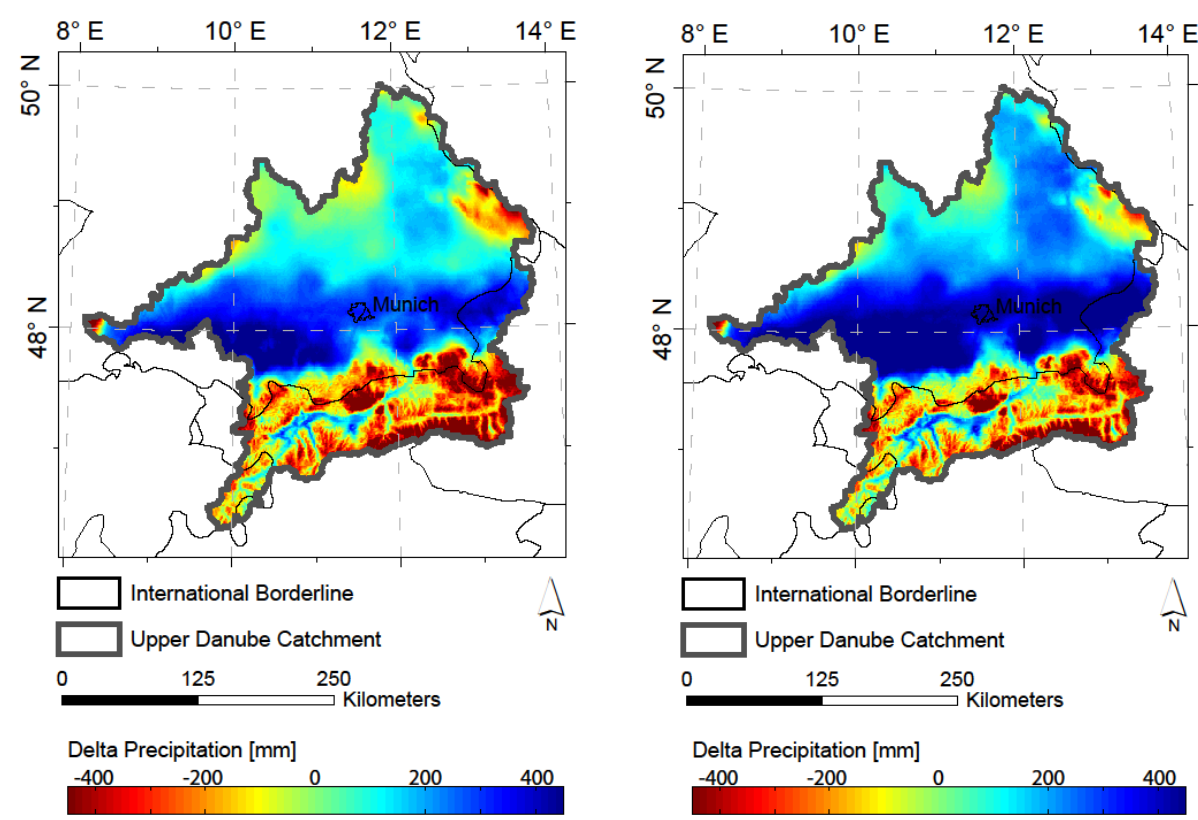

Fig. 9. Over- and underestimation of annual simulated 2-way coupled PROMET/MM5 (left panel) and NOAH/MM5 (right panel) precipitation in the Upper Danube catchment, downscaled to $1 \mathrm{~km}$ by using SCALMET and subtracted from measurements.

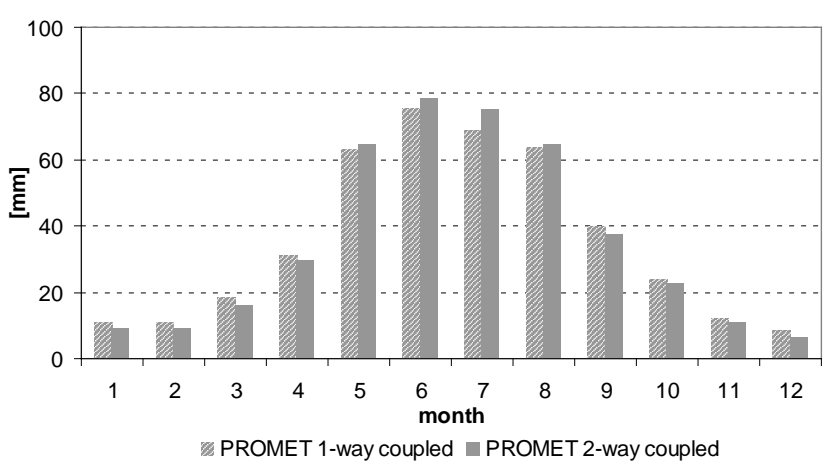

Fig. 10. Monthly mean evapotranspiration in the Upper Danube catchment of 1-way and 2-way coupled PROMET simulations (1996-1999).

Through that replacement, the spatial resolution of the land surface representation improved from $45 \times 45 \mathrm{~km}^{2}$ (Noah-LSM) to $1 \times 1 \mathrm{~km}^{2}$ (PROMET). SCALMET is used as an interface between PROMET and the atmospheric part of MM5, scaling the fluxes between both models. When comparing the land surface fluxes between Noah-LSM and PROMET, both driven with same meteorological data for the simulation period from 1996-1999, it was shown that different spatial scales and assumptions between Noah-LSM and PROMET lead to different simulation results of latent and sensible heat, as well as long-wave emission and short-wave reflection. Thereby, PROMET evapotranspiration was lower, while sensible heat flux tended to be higher. By applying the 2-way coupling between PROMET and MM5, the atmo- sphere responded to the changed lower boundary conditions. As a result, simulated mean annual temperature changed from $5.93{ }^{\circ} \mathrm{C}$ (NOAH/MM5) to $6.65^{\circ} \mathrm{C}$ (PROMET/MM5) due to the increased amounts of incoming solar radiation and less evaporative cooling leading to increased sensible heat flux. Compared to meteorological measurements $\left(6.78^{\circ} \mathrm{C}\right)$, simulated near-surface air temperature improved also for monthly and diurnal courses. Particularly, afternoon heating was modelled more adequately by the use of the PROMET model. The impact of the PROMET land surface scheme on changes in the atmosphere is strongest in summer, when energy transformation at the land surface strongly affects atmosphere processes.

The change of the land surface predominantly affects convective precipitation. Overall, precipitation was reduced mainly due to decreased convective precipitation in summer, which can be explained by the rise of the planetary boundary layer due to more sensible heat flux. As a result, the moisture content of air masses is reduced, and cloud fraction and convection are finally impeded. However, simulated precipitation shows a spatial shift northwards into the Alpine forelands, following the coarse description of the topography in MM5, when compared to measurements in the Upper Danube catchment.

The strong overestimation of Noah-LSM annual runoff for the Upper Danube catchment $\left(1712 \mathrm{~m}^{3} \mathrm{~s}^{-1}\right)$ was improved to $1583 \mathrm{~m}^{3} \mathrm{~s}^{-1}$ when using the 1-way coupled hydrological land surface model PROMET, due to higher evapotranspiration rates. When 2-way coupling PROMET with MM5, runoff again improved to $1474 \mathrm{~m}^{3} \mathrm{~s}^{-1}$ without the application of a bias correction in comparison to 
gauge measurements in Achleiten $\left(1412 \mathrm{~m}^{3} \mathrm{~s}^{-1}\right)$, due to multiple impacts of the 2-way coupling approach on the atmosphere (planetary boundary layer, cloud fraction, solar radiation, precipitation, temperature) and resulting feedback effects (such as decreased soil moisture and increased evapotranspiration).

Acknowledgements. The research described in this paper was carried out at the Department of Geography of the LudwigMaximilians-University in Munich, Germany, as part of the GLOWA-Danube project, which was funded by BMBF from 2000 to 2010. This support is gratefully acknowledged.

Edited by: H. Cloke

\section{References}

Chen, F. and Dudhia, J.: Coupling an Advanced Land SurfaceHydrology Model with the Penn State-NCAR MM5 Modeling Systemm, Part I: Model Implementation and Sensitivity, Mon. Weather Rev., 129, 569-585, 2001.

Garcia-Quijano, J. F. and Barros, A. P.: Incorporating canopy physiology into a hydrological model: photosynthesis, dynamic respiration, and stomatal sensitivity, Ecol. Modell., 185, 29-49, doi:10.1016/j.ecolmodel.2004.08.024, 2005.

Grell, G. A., Dudhia, J., and Stauffer, D. R.: A description of the fifth-generation Penn State/NCAR mesoscale model (MM5), NCAR/TN-398+STR, 138 pp., 1994.

Hagemann, S., Botzet, M., and Machenhauer, B.: The summer drying problem over south-eastern europe: sensitivity of the limited area model HIRHAM4 to improvements in physical parameterization and resolution, Phys. Chem. Earth B, 26, 391-396, doi:10.1016/s1464-1909(01)00024-7, 2001.

Henderson-Sellers, A., Dickinson, R. E., and Pitman, A. J.: Atmosphere-landsurface modelling, Math. Comput. Modell., 21, 5-10, doi:10.1016/0895-7177(95)00045-4, 1995.

Henderson-Sellers, A., McGuffie, K., and Pitman, A. J.: The Project for Intercomparison of Land-surface Parametrization Schemes (PILPS): 1992 to 1995, Clim. Dynam., 12, 849-859, 1996.

Kuchment, L. S., Demidov, V. N., and Startseva, Z. P.: Coupled modeling of the hydrological and carbon cycles in the soil-vegetation-atmosphere system, J. Hydrol., 323, 4-21, doi:10.1016/j.jhydrol.2005.08.011, 2006.

Kunstmann, H., Jung, G., Wagner, S., and Clottey, H.: Integration of atmospheric sciences and hydrology for the development of decision support systems in sustainable water management, Phys. Chem. Earth A/B/C, 33, 165-174, doi:10.1016/j.pce.2007.04.010, 2008.

Ludwig, R. and Mauser, W.: Modelling catchment hydrology within a GIS based SVAT-model framework, Hydrol. Earth Syst. Sci., 4, 239-249, doi:10.5194/hess-4-239-2000, 2000.

Ludwig, R., Probeck, M., and Mauser, W.: Mesoscale water balance modelling in the Upper Danube watershed using sub-scale land cover information derived from NOAA-AVHRR imagery and GIS-techniques, Phys. Chem. Earth A/B/C, 28, 1351-1364, doi:10.1016/j.pce.2003.09.011, 2003.

Marke, T., Mauser, W., Pfeiffer, A., and Zängl, G.: A pragmatic approach for the downscaling and bias correction of regional cli- mate simulations: evaluation in hydrological modeling, Geosci. Model Dev., 4, 759-770, doi:10.5194/gmd-4-759-2011, $2011 \mathrm{a}$.

Marke, T., Mauser, W., Pfeiffer, A., Zängl, G., and Jacob, D.: The effect of downscaling on river runoff modeling: a hydrological case study in the Upper Danube Watershed, Hydrol. Earth Syst. Sci. Discuss., 8, 6331-6384, doi:10.5194/hessd-8-63312011, $2011 \mathrm{~b}$.

Mauser, W. and Bach, H.: PROMET - Large scale distributed hydrological modelling to study the impact of climate change on the water flows of mountain watersheds, J. Hydrol., 376, 362377, doi:10.1016/j.jhydrol.2009.07.046, 2009.

Mölders, N. and Raabe, A.: Testing the effect of a twoway-coupling of a meteorological and a hydrologic model on the predicted local weather, Atmos. Res., 45, 81-107, doi:10.1016/s0169-8095(97)00035-5, 1997.

Muerth, M. and Mauser, W.: Rigorous evaluation of a soil heat transfer model for mesoscale climate change impact studies, Environ. Modell. Softw., 35, 149-162, doi:10.1016/j.envsoft.2012.02.017, 2012.

Pfeiffer, A. and Zängl, G.: Validation of climate-mode MM5simulations for the European Alpine Region, Theor. Appl. Climatol., 101, 93-108, doi:10.1007/s00704-009-0199-5, 2010.

Pitman, A. J.: The evolution of, and revolution in, land surface schemes designed for climate models, Int. J. Climatol., 23, 479510, doi:10.1002/joc.893, 2003.

Pitman, A. J. and Henderson-Sellers, A.: Recent progress and results from the project for the intercomparison of landsurface parameterization schemes, J. Hydrol., 212-213, 128-135, doi:10.1016/s0022-1694(98)00206-6, 1998.

Schulla, J. and Jasper, K.: Model description of WaSiM-ETH, Institute of Geography, ETH Zürich, 1999.

Senatore, A., Mendicino, G., Smiatek, G., and Kunstmann, H.: Regional climate change projections and hydrological impact analysis for a Mediterranean basin in Southern Italy, J. Hydrol., 399, 70-92, doi:10.1016/j.jhydrol.2010.12.035, 2011.

Uppala, S. M., Kallberg, P. W., Simmons, A. J., Andrae, U., Bechtold, V. D. C., Fiorino, M., Gibson, J. K., Haseler, J., Hernandez, A., Kelly, G. A., Li, X., Onogi, K., Saarinen, S., Sokka, N., Allan, R. P., Andersson, E., Arpe, K., Balmaseda, M. A., Beljaars, A. C. M., Berg, L. V. D., Bidlot, J., Bormann, N., Caires, S., Chevallier, F., Dethof, A., Dragosavac, M., Fisher, M., Fuentes, M., Hagemann, S., Hólm, E., Hoskins, B. J., Isaksen, L., Janssen, P. A. E. M., Jenne, R., McNally, A. P., Mahfouf, J.-F., Morcrette, J.-J., Rayner, N. A., Saunders, R. W., Simon, P., Sterl, A., Trenberth, K. E., Untch, A., Vasiljevic, D., Viterbo, P., and Woollen, J.: The ERA-40 Re-analysis, Q. J. Roy. Meteorol. Soc., 131, 2961-3012, doi:10.1256/qj.04.176, 2005.

van den Hurk, B., Best, M., Dirmeyer, P., Pitman, A., Polcher, J., and Santanello, J.: Acceleration of Land Surface Model Development over a Decade of Glass, B. Am. Meteorol. Soc., 92, 15931600, doi:10.1175/bams-d-11-00007.1, 2011.

Wood, E. F., Lettenmaier, D. P., Liang, X., Lohmann, D., Boone, A., Chang, S., Chen, F., Dai, Y., Dickinson, R. E., Duan, Q., Ek, M., Gusev, Y. M., Habets, F., Irannejad, P., Koster, R., Mitchel, K. E., Nasonova, O. N., Noilhan, J., Schaake, J., Schlosser, A., Shao, Y., Shmakin, A. B., Verseghy, D., Warrach, K., Wetzel, P., Xue, Y., Yang, Z.-L., and Zeng, Q.-C.: The Project for Intercomparison of Land-surface Parameterization Schemes (PILPS) Phase 2(c) Red-Arkansas River basin experiment: 1. Experiment description 
and summary intercomparisons, Global Planet. Change, 19, 115135, doi:10.1016/s0921-8181(98)00044-7, 1998.

Zabel, F., Mauser, W., Marke, T., Pfeiffer, A., Zängl, G., and Wastl, C.: Inter-comparison of two land-surface models applied at different scales and their feedbacks while coupled with a regional climate model, Hydrol. Earth Syst. Sci., 16, 1017-1031, doi:10.5194/hess-16-1017-2012, 2012.

Zängl, G.: An improved method for computing horizontal diffusion in a sigma-coordinate model and its application to simulations over mountainous topography, Mon. Weather Rev., 130, 14231432, 2002.
Zängl, G.: To what extent does increased model resolution improve simulated precipitation fields? A case study of two north-Alpine heavy-rainfall events, Meteorol. Z., 16, 571-580, 2007a.

Zängl, G.: Interaction between Dynamics and Cloud Microphysics in Orographic Precipitation Enhancement: A HighResolution Modeling Study of Two North Alpine HeavyPrecipitation Events, Mon. Weather Rev., 135, 2817-2840, doi:10.1175/mwr3445.1, 2007b. 